\title{
Soybean mosaic virus Helper Component-Protease Alters Leaf Morphology and Reduces Seed Production in Transgenic Soybean Plants
}

\author{
Hyoun Sub Lim, Tae Seok Ko, Houston A. Hobbs, Kris N. Lambert, Jun Myoung Yu, Nancy K. McCoppin, \\ Schuyler S. Korban, Glen L. Hartman, and Leslie L. Domier
}

First, third, fourth, fifth, sixth, eighth, and ninth authors: Department of Crop Sciences, University of Illinois, Urbana 61801; second and seventh authors: Department of Natural Resources and Environmental Sciences, University of Illinois, Urbana 61801; sixth, eighth, and ninth authors: United States Department of Agriculture-Agricultural Research Service, Urbana, IL 61801.

Current address of H. S. Lim: Department of Plant and Microbial Biology, University of California at Berkeley 94720.

Current address of T. S. Ko: Department of Plant Biology, University of Minnesota, St. Paul 55108.

Current address of J. M. Yu: Department of Agronomy, Iowa State University, Ames 50011.

Accepted for publication 12 September 2006.

\section{ABSTRACT}

Lim, H. S., Ko, T. S., Hobbs, H. A., Lambert, K. N., Yu, J. M., McCoppin, N. K., Korban, S. S., Hartman, G. L., and Domier, L. L. 2007. Soybean mosaic virus helper component-protease alters leaf morphology and reduces seed production in transgenic soybean plants. Phytopathology 97:366-372.

Transgenic soybean (Glycine max) plants expressing Soybean mosaic virus (SMV) helper component-protease (HC-Pro) showed altered vegetative and reproductive phenotypes and responses to SMV infection. When inoculated with SMV, transgenic plants expressing the lowest level of HC-Pro mRNA and those transformed with the vector alone initially showed mild SMV symptoms. Plants that accumulated the highest level of SMV HC-Pro mRNA showed very severe SMV symptoms initially, but after 2 weeks symptoms disappeared, and SMV titers were greatly reduced. Analysis of SMV RNA abundance over time with region-specific probes showed that the HC-Pro region of the SMV genome was degraded before the coat protein region. Transgenic soybean plants that expressed SMV HC-Pro showed dose-dependent alterations in unifoliate leaf morphologies and seed production where plants expressing the highest levels of HC-Pro had the most deformed leaves and the lowest seed production. Accumulation of microRNAs (miRNAs) and mRNAs putatively targeted by miRNAs was analyzed in leaves and flowers of healthy, HC-Pro-transgenic, and SMV-infected plants. Neither expression of SMV HC-Pro nor SMV infection produced greater than twofold changes in accumulation of six miRNAs. In contrast, SMV infection was associated with twofold or greater increases in the accumulation of four of seven miRNA-targeted mRNAs tested.

Additional keywords: posttranscriptional gene silencing.
Plant virus infections cause disease by perturbing physiological and regulatory processes in host cells. The disruption of posttranscriptional gene silencing (PTGS), an innate and highly adaptive antiviral defense, by virus-encoded PTGS suppressors has been shown to have pleiotropic effects on plant development, morphology, and reproduction (6). Indeed, ectopic expression of virus suppressors of PTGS in plants often results in vegetative and reproductive phenotypes similar to those produced by infection with the virus from which the gene was derived $(3,21,26)$. For example, expression of the PTGS suppressors encoded by open reading frame 0 (ORF0) of Potato leafroll virus (PLRV), p23 of Citrus tristeza virus, p19 of Tomato bushy stunt virus, and $\mathrm{P} 1$ protease-helper component-protease (P1/HC-Pros) of Tobacco etch virus (TEV) or Turnip mosaic virus (TuMV) has been shown to induce symptoms in plants, to enhance accumulation and severity of symptoms induced by unrelated viruses, or both $(8,15,17,27,31,35)$.

PTGS is found in all eukaryotes, and is activated by doublestranded RNA (dsRNA) produced during virus infection,

Corresponding author: L. L. Domier; E-mail address: ldomier@uiuc.edu

DOI: 10.1094/PHYTO-97-3-0366

This article is in the public domain and not copyrightable. It may be freely reprinted with customary crediting of the source. The American Phytopathological Society, 2007. transcription of inverted repeats, or conversion of aberrantly expressed RNAs to dsRNA by host-encoded RNA-dependent RNA polymerases (14). Once induced, PTGS results in degradation of RNA molecules with sequences homologous to the dsRNAs (5). Specificity is imparted by short (21 to $24 \mathrm{nt}$ ) smallinterfering RNAs (siRNAs) produced from dsRNA by an RNase III-like enzyme called Dicer (7). siRNAs act as guides in RNAinduce silencing complexes (RISCs) to direct the degradation of complementary RNA sequences (5).

In addition to suppressing antiviral defenses, viral suppressors of PTGS also interfere with activities of two additional classes of short RNAs, transacting small interfering RNAs (ta-siRNAs) and microRNAs (miRNAs). The latter group has been shown to regulate gene expression by cleavage separately or in combination with translational repression of homologous mRNAs (36). Several studies have reported that miRNA regulation of gene expression is important in plant development, stress response, and hormone signaling (10). While siRNAs are derived from doubled-stranded versions of the RNAs they regulate, miRNAs are produced from independently transcribed host RNAs that fold into hairpin structures that are subsequently processed and incorporated into RISCs. In wild-type plants, nonselected strands of short dsRNAs produced by Dicer are often rapidly degraded (4). In several instances, expression of potyviral HC-Pro coding regions in transgenic plants has enhanced accumulation of the selected strand of miRNAs and suppressed cleavage of targeted mRNAs 
$(8,17,22)$. Phenotypes associated with expression of virusencoded PTGS suppressors mentioned above have been attributed to changes in mRNA accumulation that result from disruptions in these developmentally important small RNA pathways (6).

Soybean mosaic virus (SMV), a member of the family Potyviridae, possesses an approximately $10-\mathrm{kb}$ positive-sense single-stranded RNA genome, and depending on the virus isolate and soybean genotype, can reduce the number and size of seeds produced and cause severe leaf deformities and seed discoloration (16). Like other members of the family Potyviridae, HC-Pro of SMV has been shown to enhance the accumulation of heterologous viruses (39), suppress silencing of GUS transgenes (19), and suppress endogenous silencing of chalcone synthase genes, which results in seed coat mottling characteristic of SMV infections $(32,34)$. Because expression of TuMV P1/HC-Pro in transgenic Arabidopsis alters floral development and reduces fertility (17), we tested the hypothesis that SMV HC-Pro is primarily responsible for reduced seed set in SMV-infected plants. In addition, we assessed the effects of expression of SMV HC-Pro in transgenic soybean plants on SMV symptom severity, leaf morphology, and miRNA and mRNA accumulation.

\section{MATERIALS AND METHODS}

Virus isolates and plant materials. SMV strain G5 was obtained from J. Hill (Iowa State University, Ames). Transgenic soybean lines expressing the SMV G5 HC-Pro (LG5-1, LG5-2, and LG5-3) and GUS coding regions were previously developed in our laboratory (19). HC-Pro expression levels in transgenic lines LG5-1 and LG5-2 did not differ significantly, but HC-Pro mRNA levels were 10-fold higher in LG5-1 than in LG53 (19). Plant age was counted from the first day following separation of unifoliate leaves. For virus inoculations, young symptomatic leaves were ground in $0.05 \mathrm{M}$ sodium phosphate buffer ( $\mathrm{pH}$ 6.9), 1:10 (weight/vol), and used for inoculation. Fiveday-old unifoliate leaves were dusted with 600 mesh carborundum (B.C.S. Co., Thompson, CT) and rubbed with gauze pads dipped in inoculum. Leaflets from trifoliate leaves were collected for RNA extraction as previously described (19).

Plant growth and seed production. Soybean plants were grown in a 50:50 soil/Sunshine Mix (Sun Grow Horticulture, Bellevue, WA) in a greenhouse, and grown under $14 \mathrm{~h}$ photoperiod supplied by halogen lamps providing a light intensity of 100 to $180 \mu \mathrm{mol} \mathrm{m} \mathrm{m}^{-2} \mathrm{~s}^{-1}$. Two experiments were conducted to compare seed production of HC-Pro and GUS transgenic lines. In the first experiment, four plants each of LG5-1, LG5-2, LG53 , GUS (+), and nontransgenic soybean were individually grown to maturity in 30-cm-diameter pots and seed was harvested and counted. In the second experiment, 10 plants each of transgenic lines LG5-1, LG5-2, and LG5-3 and five plants each of GUS(+) and nontransgenic soybean were grown to maturity in $20-\mathrm{cm}-$ diameter pots with two plants per pot. Analysis of variance and regression analyses of the numbers of seed produced and HC-Pro expression levels were performed using Excel (Microsoft, Redmond, WA) and Win Stat (Calumet City, IL).

Quantitative real-time reverse transcriptase polymerase chain reaction (QRT-PCR) for detecting HC-Pro and coat protein (CP) regions. Minor groove-binding (MGB) nonfluorescent quencher (NFQ) probes were designed using Primer Express software (Applied Biosystem, Foster City, CA). A probe for the SMV CP region was selected at nucleotide position 8932 (NED-TGGATGGAGAGGAAC-MGBNFQ) with flanking primers (CTAATGGCGTGTGGGTGATG and GGGTTTCAGCGGATATTCAATC). Primers and probes for SMV HC-Pro and soybean actin 1 (SAcl) were described previously (19). In seed production studies, HC-Pro expression levels were assessed in 5-day-old unifoliate leaves from individual transgenic plants by QRT-PCR. Total RNA was extracted from $50 \mathrm{mg}$ of frozen and finely powdered tissue using Trizol reagent (Invitrogen, Carlsbad, CA) and reverse-transcribed $(2 \mu \mathrm{g})$ using an oligo(dT) primer and Superscript II reverse transcriptase (Invitrogen), and then diluted with $50 \mu$ of water per reaction.

Because 3'-terminal fragments of RISC-mediated cleavage often are stable and can be detected by blot hybridization and RT-PCR $(13,17)$, the MGB probes specific for HC-Pro and CP coding regions were used to determine whether the decline of SMV RNA titers and attenuation of SMV symptoms were caused by overall failure of suppression of PTGS or by sequence-specific degradation of the HC-Pro coding region. Leaflets were collected daily from 20 SMV-infected HC-Pro-transgenic (LG5-1) and 20 SMV-infected GUS transgenic plants. Total RNA was extracted and reverse-transcribed using primers specific for HC-Pro (TGAGCATGTATGCAGCTGTT) and CP (CACAAACATTATTTGGTGATGC) coding regions. SAcl was used as an internal standard. A full-length clone of SMV G2 was used as a copy number standard for SMV HC-Pro and CP coding regions. Standard curves were established using 10-fold dilutions over a $10^{7}$ range of the plasmid DNA. To confirm the differential accumulation of HC-Pro and CP coding regions, total RNA $(1 \mu \mathrm{g})$ extracted from three 20-day-old SMV-infected LG5-1 transgenic plants was spotted on nylon membranes and separately hybridized with ${ }^{32} \mathrm{P}$-labeled probes specific for the HC-Pro (nt 1055 to 2426) and CP (nt 8533 to 9312) coding regions (19). Membranes were hybridized and washed as described previously (19). Hybridization was detected using a PhosphorImager (Amersham Biosciences, Piscataway, NJ).

Analysis of miRNAs and mRNAs putatively targeted by miRNAs. The affects of SMV infection and expression of SMV HC-Pro in transgenic soybean plants on the accumulation of soybean miRNA were investigated using oligonucleotide probes complementary to six miRNAs (miR156, miR159, miR160, miR165, miR167, and miR171). These miRNAs are conserved across a wide range of dicotyledonous and monocotyledonous plants including soybean (11). The sequences of the probes used were as follows: miR156, GTGCTCACTCTCTTCTGTCA; miR159, TAGAGCTCCCTTCAATCCAAA; miR160, TGGCATACAGGGAGCCAGGCT; miR165, GGGGGATGAAGCCTGGTCCGA; miR167, TAGATCATGCTGGCAGCTTCA; and miR171, GATATTGGCGCGGCTCAATCA. An oligonucleotide probe for the highly conserved U6 small nuclear RNA (snRNA; GACCATTTCTCGATTTGTGCGTGTC) was used as a control to normalize miRNA accumulation. Probes were labeled using T4 polynucleotide kinase and $\gamma^{32}$ P-ATP (29). Low molecular weight RNAs were purified from pools of age-matched trifoliate leaves and B2-stage flowers (25) from five plants per treatment (healthy, HC-Pro transgenic, and infected with SMV G5) using the mirVana RNA purification kit (Ambion, Austin, TX). Five micrograms of low molecular weight RNA preparations was denatured, loaded onto $15 \%$ polyacrylamide gels containing 8.5 $\mathrm{M}$ urea and $0.5 \times$ Tris-borate-EDTA (29), and run for $2 \mathrm{~h}$ at $150 \mathrm{~V}$. DNA oligonucleotides representing sense versions of the miRNAs were run as molecular weight markers. Following electrophoresis, RNAs were blotted to nylon membranes and hybridized as described previously (19). Band intensities were determined using a PhosphorImager and normalized to the hybridization intensity of the U6 snRNA probe. All low molecular weight RNA isolations and blot hybridizations were conducted at least twice with independent sets of soybean plants. mRNA accumulation levels were assigned a value of 1.0 in healthy leaves and flowers. mRNA accumulation levels for HC-Pro-transgenic and SMV-infected tissues were expressed as fold changes relative to the corresponding healthy controls. 
Assessing the impact of HC-Pro expression on the accumulation of miRNA-targeted mRNAs. Seven soybean mRNAs (Table 1) homologous to the Arabidopsis mRNAs targeted by miRNAs (miR156, miR162, miR167, miR168, miR171, miR394, and miR399) were identified by BLAST and TBLASTX searches with miRNA and Arabidopsis predicted amino acid sequences, respectively, of soybean gene index of The Institute for Genomic Research (TIGR, Rockville, MD) (18). In Arabidopsis, miR156, miR162, miR167, miR168, miR171, miR394, and miR399 target mRNAs that are involved in miRNA metabolism ( $A G O 1$ and $D C L 1$ ), embryo-specific programmed cell death $(E 2-U B C)$, and meristem identity and cell differentiation (ARF8, SPL11, and UFO) (2). Oligonucleotide primers (Table 1) were designed for each of the putative soybean targets using Primer3 (28). Soybean sequences TC214166, TC207358, TC217781, and TC227645 contained regions of complementarity to miR156, miR167, miR171, and miR394, respectively. The presence of miR162 complementarity in TC230311 was confirmed by RT-PCR using the primer complementary to miR162 (CTGGATGCAGAGGTTTATCGA) and the reverse primer for TC230311 (Table 1), which amplified a fragment of the predicted size $(2.1 \mathrm{~kb})$. The presence of miR168 and miR399 sequence complementarity in TC2154678 and TC216377, respectively, was predicted based on homology to Arabidopsis targeted mRNAs, but was not confirmed experimentally. Total RNA and low molecular weight RNAs were purified using the
mirVana RNA purification kit (Ambion) and reverse transcribed as above. mRNA accumulation was monitored by QRT-PCR using gene-specific primers and SYBR-Green master mix in a 7900HT Sequence Detection System (Applied Biosystem). The $2^{\Delta \Delta C T}$ method (20) was used to calculate relative changes in mRNA accumulation using primers for SAcl mRNA (19). mRNA accumulation levels were assigned a value of 1.0 in healthy leaves and flowers. mRNA accumulation levels for HC-Pro-transgenic and $\mathrm{SMV}$-infected tissues were expressed as fold changes relative to the corresponding healthy controls.

\section{RESULTS}

Expression of SMV HC-Pro altered SMV symptoms in a dose-dependent manner. All HC-Pro-transgenic soybean lines were susceptible to SMV infection. Symptom development was compared over time after inoculation with SMV G5 in three independent transgenic soybean lines expressing SMV G5 HCPro (Table 2). The severity and rate at which symptoms developed were related to HC-Pro expression levels (Table 2). Transgenic plants expressing the highest level of HC-Pro, LG5-1, initially developed the most severe symptoms. SMV G5 induced very mild symptoms on GUS(+) plants. Plants of transgenic lines LG5-2 and LG5-3 developed symptoms less severe than LG5-1, but more severe than GUS(+) controls on fourth and sixth trifoliate leaves, respectively.

TABLE 1. Primers used for detection of soybean mRNAs homologous to microRNA (miRNA)-targeted mRNAs in Arabidopsis

\begin{tabular}{|c|c|c|c|c|}
\hline miRNA & $\begin{array}{l}\text { Putative } \\
\text { soybean } \\
\text { target }\end{array}$ & Target primers & $\begin{array}{l}\text { Arabidopsis target } \\
\text { (product) }\end{array}$ & $\begin{array}{l}\text { Soybean miRNA and putative target } \\
\text { complementarity }{ }^{\mathrm{v}}\end{array}$ \\
\hline $\operatorname{miR} 156$ & TC214166 & $\begin{array}{l}\text { GATAGCAGCAATCGCTTTCAAGACTTTCAG } \\
\text { GCAGTCTGGTACAAACACCATTCGGGAAAT }\end{array}$ & At1g27360 (SPL11) & $\begin{array}{l}3^{\prime} \text { - CACGAGUGAGAGAAGACAGU-5' } \\
|||||||||||||||||| \mid \\
238 \text {-GUGCUCUCUCUCUUCUGUCA-257 }\end{array}$ \\
\hline $\operatorname{miR} 162$ & TC230311 & $\begin{array}{l}\text { AGACTCTGCCAATGCATCCT } \\
\text { GCCAAATTGCCAATACGACT }\end{array}$ & At1g01040 (DCL1) & RT-PCR positive ${ }^{y}$ \\
\hline $\operatorname{miR} 167$ & TC207358 & $\begin{array}{l}\text { AGGAGTTGGCACAGATGTTTGGTATTGAGG } \\
\text { CATCGTTCTCCCTGTCGACGAATACAAGCT }\end{array}$ & At5g37020 (ARF8) & $\begin{array}{l}3^{\prime} \text {-AUCUAGUACGACCGUCGAAGU-5' } \\
|||||||||||||||||| \\
\text { 505-UAGAUCAGGCUGGCAGCUUGU-524 }\end{array}$ \\
\hline $\operatorname{miR} 168$ & TC215467 & $\begin{array}{l}\text { TGGCTTCGCAAGACTATCCT } \\
\text { GTTCCTGCCTATGAGCTTGG }\end{array}$ & At1g48410 (AGO1)y & $\mathrm{ND}^{\mathrm{z}}$ \\
\hline $\operatorname{miR} 171$ & TC217781 & $\begin{array}{l}\text { GATGCCGGTAATCTGGAACTCGCGCATG } \\
\text { AAGGCTTCCCAATGGGAGAAAGTTGGTGAT }\end{array}$ & At4g00150 (SCL6) & 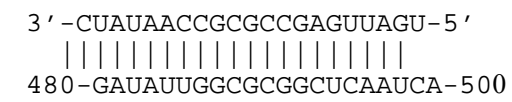 \\
\hline $\operatorname{miR} 394$ & TC227645 & $\begin{array}{l}\text { CGGCTTAGTTTGCTTCCTTG } \\
\text { AGCAACACGAGACCAGACT }\end{array}$ & At1g27340 (UFO) & $\begin{array}{l}3^{\prime} \text { - CCTCCACCUGUCUUACGGUU-5' } \\
|||||||||||||||||||||| \mid \\
1157 \text { - GGAGGUUGACAGAAUGCCAA-1176 }\end{array}$ \\
\hline $\operatorname{miR} 399$ & TC216377 & $\begin{array}{l}\text { CAAATTCTGCCCAGTCCCTA } \\
\text { GGCCACAAGTGTCCAAATCT }\end{array}$ & At2g33770 (E2-UBC $)^{\mathrm{y}}$ & ND \\
\hline
\end{tabular}

v Complementarity (vertical lines) between miRNA (top) and soybean mRNA (bottom) sequences.

${ }^{\text {w }}$ The Institute for Genomic Research (TIGR) Gene Index identifier is available online from The Institute for Genomic Research, Rockville, MD.

$x$ Allen et al. (2).

y Confirmed using real time-polymerase chain reaction with oligonucleotide primer complementary to miR 162 primer and lower target primer.

z $\mathrm{ND}=$ not determined.

TABLE 2. Soybean mosaic virus (SMV) symptoms in transgenic plants inoculated with SMV G5

\begin{tabular}{|c|c|c|c|c|}
\hline \multirow[b]{2}{*}{ Trifoliate } & \multicolumn{4}{|c|}{ Symptom severity in four soybean lines ${ }^{\mathrm{y}}$} \\
\hline & $\begin{array}{c}\text { GUS(+) } \\
\text { HC-Pro }=0^{z}\end{array}$ & $\begin{array}{c}\text { LG5-3 } \\
\text { HC-Pro = } 1^{z}\end{array}$ & $\begin{array}{c}\text { LG5-2 } \\
\text { HC-Pro = } 4\end{array}$ & $\begin{array}{c}\text { LG5-1 } \\
\text { HC-Pro = } 12\end{array}$ \\
\hline Third & 3 & 3 & 3 & 4 \\
\hline Fourth & 3 & 3 & 4 & 4 \\
\hline Fifth & 3 & 3 & 4 & 4 \\
\hline Sixth & 3 & 4 & 4 & 3 \\
\hline Seventh & 3 & 4 & 2 & 1 \\
\hline Eighth & 3 & 4 & 1 & 1 \\
\hline Ninth & 2 & 4 & 1 & 1 \\
\hline
\end{tabular}

y 1 = asymptomatic; 2 = mosaic; $3=$ mosaic and mottling; 4 = mosaic, mottling, and rugosity; and $5=$ mosaic, mottling, rugosity, and chlorosis.

${ }^{\text {z }}$ Helper component-protease (HC-Pro) expression level relative to LG5-3. 
High-level expression of SMV HC-Pro resulted in recovery from SMV infection in transgenic plants. When LG5-1 plants were infected with SMV G5, no symptoms were observed on the seventh trifoliate, emerging at about 30 days postinoculation (dpi), nor on subsequent leaves (Table 2).

This was observed in spite of the fact that the third, fourth, and fifth trifoliates exhibited severe symptoms. While SMV RNA copy numbers decreased in asymptomatic leaves of LG5-1 and LG5-2, they remained high in symptomatic leaves of LG5-3 (Table 3). SMV RNA copy numbers were approximately 50-fold lower in asymptomatic leaves of LG5-1 compared with those of SMV-infected GUS(+) plants (Table 3).

Recovery from SMV infection in transgenic plants expressing high levels of SMV HC-Pro mRNA resulted from preferential degradation of the HC-Pro coding region. In LG5-1 plants inoculated with SMV G5, severe symptoms were observed on fully expanded third trifoliates at $20 \mathrm{dpi}$, but symptoms gradually disappeared by the seventh trifoliate leaves (Table 2). In 5- to 10day-old leaflets of third trifoliate leaves, SMV G5 HC-Pro and CP copy numbers did not differ significantly between HC-Pro- and GUS-transgenic lines (Table 4). For 15- to 20-day-old leaves, significant reductions in copy numbers of the HC-Pro coding region were detected in $\mathrm{HC}$-Pro transgenic lines even though $\mathrm{CP}$ region copy numbers increased (Table 4). In contrast, the copy numbers of both the $\mathrm{CP}$ and HC-Pro regions remained high in GUS(+) plants, indicating there was no preferential degradation of the HC-Pro coding region in the SMV-infected control line. Dot blots of total RNA from 20-day-old HC-Pro transgenic plants confirmed the differential accumulation of the HC-Pro and $\mathrm{CP}$ coding regions in LG5-1 plants (data not shown). Although degradation started in the HC-Pro region of transgenic soybean plants in the third and fourth trifoliates, symptoms re-mained more severe in the third, fourth, and fifth trifoliates of HC-Protransgenic plants than in the GUS-transgenic line (Table 2).

The threshold cycle $\left(\mathrm{C}_{\mathrm{T}}\right)$ values of HC-Pro mRNA in 40-dayold noninfected HC-Pro transgenic plants did not differ significantly between young leaves (seventh trifoliate) and old leaves (third trifoliate) (Table 5). Hence, HC-Pro mRNA accumulation was not affected by silencing in those HC-Pro-

TABLE 3. Soybean mosaic virus (SMV) RNA copy numbers in seventh trifoliates of soybean plants infected with SMV G5 at 30 days postinoculation

\begin{tabular}{lcc}
\hline Soybean line & Copies SMV RNA per pg & Symptoms $^{\mathrm{x}}$ \\
\hline LG5-1 & $0.05 \pm 0.01^{\mathrm{y}}$ & 1 \\
LG5-2 & $0.20 \pm 0.05$ & 2 \\
LG5-3 & $1.95 \pm 0.25$ & 4 \\
GUS $(+)^{\mathrm{z}}$ & $2.58 \pm 0.31$ & 3 \\
\hline
\end{tabular}

${ }^{\mathrm{x}} 1=$ asymptomatic; $2=$ mosaic; $3=$ mosaic and mottling; $4=$ mosaic, mottling, and rugosity; and $5=$ mosaic, mottling, rugosity, and chlorosis.

${ }^{y}$ Mean and standard error of three readings.

${ }^{\mathrm{z}}$ Soybean line transformed with pCAMBIA1305.2.

TABLE 4. Changes in copy numbers of RNA regions encoding coat protein (CP) and helper component-protease (HC-Pro) in third trifoliates over time after inoculation with Soybean mosaic virus (SMV) strain G5

\begin{tabular}{lcccc}
\hline & \multicolumn{4}{c}{ Copy numbers per pg total RNA } \\
\cline { 2 - 5 } & \multicolumn{2}{c}{ LG5-1 $^{\mathrm{w}}$} & \multicolumn{2}{c}{ GUS $(+)^{\mathrm{x}}$} \\
\hline Leaf age (days) & HC-Pro & $\mathrm{CP}$ & HC-Pro & $\mathrm{CP}$ \\
$5-10$ & $2.5 \mathrm{a}^{\mathrm{y}}$ & $2.5 \mathrm{~b}^{\mathrm{z}}$ & $2.4 \mathrm{a}$ & $2.4 \mathrm{~b}$ \\
$15-20$ & $0.4 \mathrm{~b}$ & $4.2 \mathrm{a}$ & $2.6 \mathrm{a}$ & $2.2 \mathrm{~b}$ \\
$25-30$ & $0.2 \mathrm{~b}$ & $0.3 \mathrm{c}$ & $2.7 \mathrm{a}$ & $2.7 \mathrm{~b}$ \\
\hline
\end{tabular}

${ }^{w}$ Average of 20 T2 plants of LG5-1.

$x$ Soybean line transformed with pCAMBIA1305.2.

y Least significant difference (LSD; $\alpha=0.05)=0.47$.

${ }^{\mathrm{z}} \operatorname{LSD}(\alpha=0.05)=0.66$ transgenic plants that were not infected with SMV during the course of the experiment.

Expression of SMV HC-Pro in transgenic soybean altered leaf morphology and seed production in a dose-dependent manner. Unifoliate leaf morphologies and seed production were evaluated in three transgenic soybean lines expressing SMV G5 HC-Pro. Plants of transgenic line LG5-1 had the most severe leaf distortions and decreased length/width ratios for unifoliate leaf blades (Fig. 1A). Plants of transgenic line LG5-1 had decreased length/width ratios for leaf blades compared with those of GUS(+) plants. This change in length/width ratios for unifoliate

TABLE 5. Accumulation of helper component-protease (HC-Pro) mRNA in healthy 40-day-old LG5-1 transgenic plants

\begin{tabular}{lcl}
\hline & \multicolumn{2}{c}{$\mathrm{C}_{\mathrm{T}}{ }^{\mathrm{x}}$ value } \\
\cline { 2 - 3 } Leaf & HC-Pro & Actin1 \\
\hline Third & $22.9 \mathrm{a}^{\mathrm{y}}$ & $19.8 \mathrm{a}^{\mathrm{z}}$ \\
Fourth & $22.1 \mathrm{a}$ & $19.7 \mathrm{a}$ \\
Fifth & $23.3 \mathrm{a}$ & $19.5 \mathrm{a}$ \\
Sixth & $21.1 \mathrm{a}$ & $20.2 \mathrm{a}$ \\
Seventh & $22.9 \mathrm{a}$ & $19.8 \mathrm{a}$ \\
\hline
\end{tabular}

$\mathrm{x}$ Threshold cycle.

${ }^{\mathrm{y}}$ Least significant difference $(\mathrm{LSD} ; \alpha=0.05)=2.3$.

${ }^{\mathrm{z}} \operatorname{LSD}(\alpha=0.05)=1.6$.
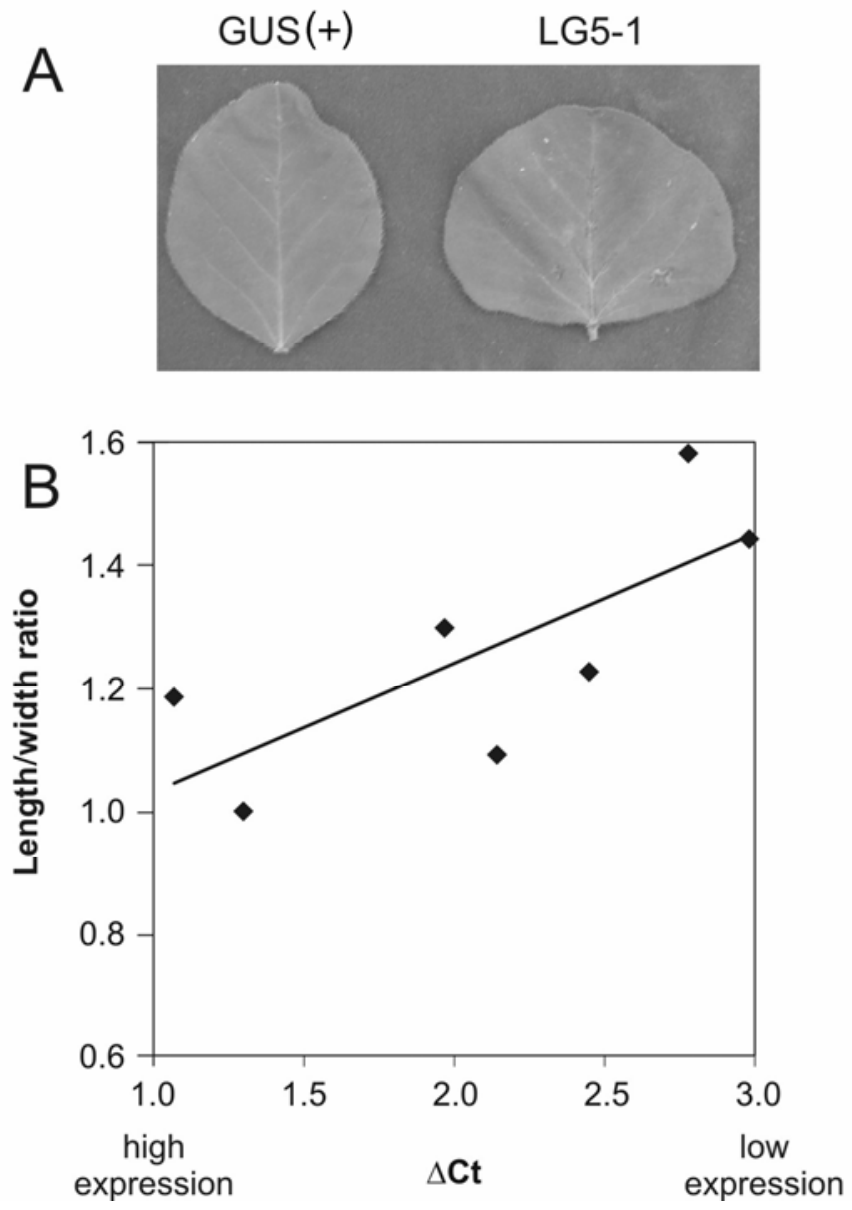

Fig. 1. Differences in unifoliate leaf morphology between transgenic lines expressing $\beta$-glucuronidase (GUS)(+) and Soybean mosaic virus (SMV) G5 helper component-protease (HC-Pro). A, Unifoliate leaves from transgenic soybean lines expressing (left) GUS(+) and (right) SMV HC-Pro, LG5-1. B, Length/width ratios of unifoliate leaf blades from GUS (+) transgenic soybean plants and transgenic soybean lines expressing SMV HC-Pro, plotted relative to the $\Delta \mathrm{C}_{\mathrm{T}}$ values $\left(\mathrm{C}_{\mathrm{T}}\right.$ of highest expressing plant was subtracted from each $\mathrm{C}_{\mathrm{T}}$, determined from 5-day-old unifoliate leaves). Diamonds represent ratios from individual leaves. The solid regression line was calculated from the data. 
leaf blades was significantly correlated with the level of expression of SMV G5 HC-Pro in transgenic plants (correlation coefficient $=0.74, \rho<0.05)($ Fig. $1 \mathrm{~B})$.

The numbers of seeds produced by four plants each of LG5-1, LG5-2, LG5-3, GUS(+), and nontransgenic soybean was significantly correlated with HC-Pro expression level based on QRT-PCR values expressed as the $\log$ of the $\Delta \mathrm{C}_{\mathrm{T}}$ values $\left(\mathrm{C}_{\mathrm{T}}\right.$ of highest expressing line subtracted from each $\mathrm{C}_{\mathrm{T}}$ ) determined from 5-day-old unifoliates (correlation coefficient $=0.92, \rho<0.001$ ) (Fig. 2A). The resulting regression coefficient, $R^{2}=0.84$, suggested that the variation in HC-Pro expression explained approximately $84 \%$ of the observed variation in seed production among these lines. In a second experiment, using 10 plants of each of three transgenic SMV G5 HC-Pro lines and five GUS(+) and nontransgenic soybean plants, seed production was lower than in the first experiment, but followed a similar trend (Fig. 2B). The correlation coefficient between seeds per plant and log $\left(\Delta \mathrm{C}_{\mathrm{T}}\right)$ was 0.87 with an $R^{2}$ value of 0.77 .

SMV infection enhanced accumulation of mRNAs putatively targeted by miRNAs. To investigate the mechanisms by which SMV HC-Pro altered leaf morphology and seed

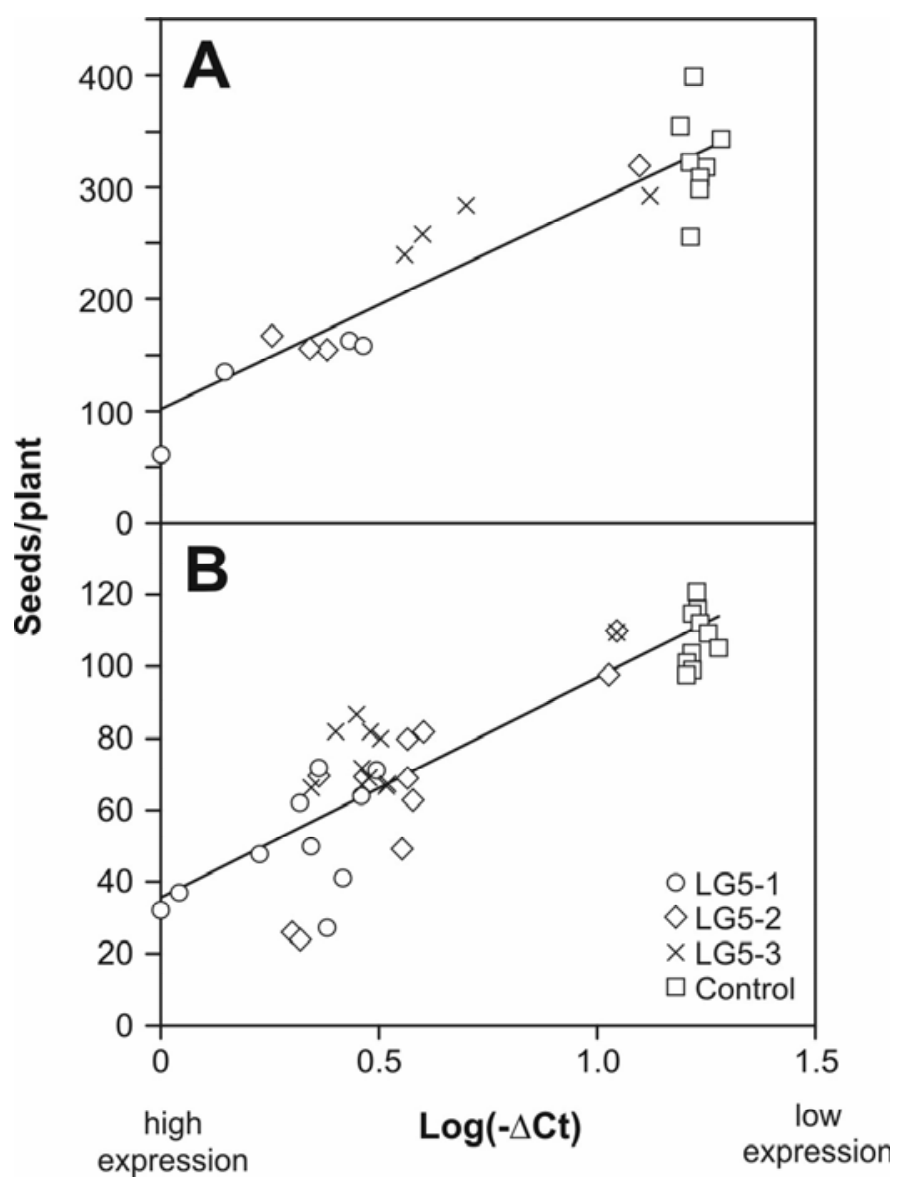

Fig. 2. Production of seed by transgenic soybean lines expressing Soybean mosaic virus (SMV) helper component-protease (HC-Pro). A, Seed production of four plants each of LG5-1, LG5-2, LG5-3, GUS(+) (expressing $\beta$-glucuronidase), and nontransgenic soybean. Individual plants were grown in 30 -cm-diameter pots. The number of seeds produced by each plant was plotted against the $\log \Delta \mathrm{C}_{\mathrm{T}}\left(\mathrm{C}_{\mathrm{T}}\right.$ of highest expressing plant was subtracted from each $\mathrm{C}_{\mathrm{T}}$, determined from 5-day-old unifoliate leaves). B, Seed production of 10 plants each of LG5-1, LG5-2, and LG5-3, and four plants each of GUS(+) and nontransgenic soybean. Two plants were grown per 20$\mathrm{cm}$-diameter pot. The number of seeds produced by each plant was plotted against the $\log (-) \Delta \mathrm{C}_{\mathrm{T}}$. Symbols represent the number of seeds produced by individual plants from each transgenic line. Controls are GUS(+) and nontransgenic soybean plants. The solid regression line was calculated from the data. production, the accumulation of six miRNAs was evaluated. Oligonucleotide probes labeled with ${ }^{32} \mathrm{P}$ complementary to miR156, miR159, miR160, miR165, miR167, and miR171 detected small RNAs of approximately $21 \mathrm{nts}$ on northern blots of low molecular weight RNAs extracted from leaves and flowers of healthy, SMV-infected, and LG5-1-transgenic soybean plants (Fig. 3A). Accumulation of miRNAs differed by less than twofold between control (healthy) and HC-Pro-transgenic and SMVinfected samples (Fig. 3A). Tissue-specific differences in miRNA accumulation were observed with two miRNAs. miR156 was present at levels 14-fold higher in leaves than in flowers. In contrast, miR160 was present at levels 2.5 -fold higher in healthy flowers than in healthy leaves.

Changes in the accumulation of soybean mRNAs homologous to Arabidopsis mRNAs that are targeted by miRNAs were similar to those observed for miRNAs in HC-Pro transgenic soybeans (Fig. 3B). SMV infection produced larger differences in mRNA accumulation. The highest responses to HC-Pro expression and SMV infection were observed in mRNAs of TC215467, a homologue of Arabidopsis ARGONAUTE1. TC215467 mRNA levels were 2.0- and 3.3-fold higher in SMV-infected leaves and flowers, respectively, than the corresponding control tissues. The accumulation of transcripts of TC217781, a homologue of Arabidopsis SCARECROW-LIKE6, and of TC227645, a homologue of Arabidopsis UNUSUAL FLORAL ORGANS, was 3.4- and 2.5-fold higher in SMV-infected than in healthy flowers, respectively (Fig. 3B). The accumulation of transcripts of TC216377, a homologue of a Drosophila miRNA-targeted ubiquitin conjugase that is involved in embryo-specific apoptosis (38), was twofold higher in infected than in healthy flowers (Fig. 3B). All of the HC-Pro transgenic samples differed from the healthy controls in mRNA accumulation by less than twofold. As with miRNAs, the accumulation of mRNAs putatively targeted by miRNAs also exhibited tissue specificity. The accumulation of mRNAs of TC207358, TC214166, TC215467, and TC227645 was 12.4-, 9.6-, 6.3-, and 3.3-fold higher in flowers than in leaves, respectively. The accumulation of mRNAs of TC230311, TC216377, and TC217781 differed by less than twofold between leaves and flowers.

\section{DISCUSSION}

In SMV-infected transgenic soybean plants, symptoms initially were most severe in plants expressing the highest levels of HCPro, but were attenuated in younger leaves. Similarly, transgenic plants expressing Cowpea aphid-borne mosaic virus or Potato virus A (PVA) HC-Pro initially showed severe symptoms when challenged with the cognate viruses followed by symptom attenuation $(23,30)$. The analysis of SMV RNA accumulation over time with probes specific for $\mathrm{HC}$-Pro and $\mathrm{CP}$ coding regions indicated that silencing of SMV RNA first targeted the HC-Pro coding region in HC-Pro transgenic soybean plants. Subsequently, the $\mathrm{CP}$ coding region of the SMV genome was degraded, resulting in lower SMV RNA accumulation in the sixth and seventh trifoliate leaves of HC-Pro transgenic plants than in GUS(+) controls. Symptom attenuation and high levels of virus resistance also have been reported in transgenic soybean plants expressing the CP gene of SMV (37) and Bean pod mottle virus (12). Recently, Nicola-Negri et al. (24) reported that expression of hairpin sequences derived from within $\mathrm{P} 1 / \mathrm{HC}$-Pro coding regions of Plum pox virus (PPV) provided resistance to PPV.

In the absence of SMV infection, HC-Pro expression was relatively stable in transgenic lines. Therefore, gene silencing must have resulted from the interaction between transcripts of the transgene and those of the virus RNA. This suggested that high levels of HC-Pro mRNA accumulation were required for triggering an antiviral silencing response. This is consistent with the model for RNA-mediated virus resistance first proposed by 
Smith et al. (33), where accumulation of transcripts above a threshold level triggers its PTGS-mediated degradation.

Virus-encoded suppressors of PTGS have been shown to induce a range of virus-like symptoms in plants (6). The HC-Pro coding region of SMV, like those of other members of the family Potyviridae, has been shown to enhance the accumulation of heterologous viruses (39), to suppress silencing of a GUS transgene (19), and to suppress silencing of chalcone synthase genes, which results in seed coat mottling characteristic of SMV infections $(32,34)$. In this study, we showed that expression of SMV HC-Pro in transgenic soybean plants resulted in significant reductions in seed production that are characteristic of SMV infection. Unlike Arabidopsis plants expressing TuMV P1/HCPro (17), no obvious floral defects were noted in HC-Pro transgenic plants. As with SMV-infected plants, HC-Pro transgenic plants produced fewer pods per node (many nodes produced no pods) and fewer seeds per pod than GUS(+) controls. In addition, the reductions in seed production were correlated with HC-Pro expression levels, as were alterations in leaf morphology and the severity of symptoms of SMV infection. Savenkov and Valkonen (30) also reported dose responses in PVA HC-Pro enhancement of PLRV titers. Leaf-shape alterations and reductions in seed quantity in SMV HC-Pro transgenic plants were consistent with the predicted role of HC-Pro in interfering with miRNA regulation.

Even though expression of SMV HC-Pro in transgenic plants significantly reduced seed production, the changes in accumulation of miRNAs and mRNAs putatively targeted by miRNAs were small. In transgenic tobacco and Arabidopsis plants, expression of P1/HC-Pro from either TEV or TuMV enhanced accumulation of miR156, miR164, miR167, and
miR171 and produced greater than twofold increases in the accumulation of most miRNA-targeted mRNAs analyzed $(8,17,22)$. In analysis of Potato virus $X$ (PVX) and TEV synergism, Pruss et al. (27) concluded that TEV HC-Pro was sufficient to produce synergistic responses with PVX, but the entire P1/HC-Pro coding region was required to prolong the accumulation (-)RNA strand of PVX. Hence, it is possible that larger differences in miRNA accumulation may have been observed if SMV P1 and HC-Pro coding regions rather than HCPro alone had been expressed in transgenic plants. However, the accumulation of miRNAs in both healthy and SMV-infected leaves and flowers were very similar, which suggests that expression of SMV P1 would not have enhanced the response in the transgenic plants. Even so, the more modest changes in miRNA accumulation in response to SMV infection and HC-Pro expression are consistent with the proposal that HCPro inhibits PTGS downstream of miRNA and siRNA production (8).

In situ hybridizations using miRNA probes have revealed spatial and temporal patterning in miRNA accumulation during development of embryo and floral primordia $(1,9)$. Hence while it is possible that small changes in RNA levels resulted in the observed phenotypes in soybean, it is more likely that SMV HCPro altered accumulation of miRNAs and mRNAs in only a subset of the cells within the tissues analyzed. These changes could have been diluted by a larger number of cells in which the specific miRNAs were not actively involved in regulating gene expression. Therefore, in situ hybridization or other cell-specific assays may be more informative in elucidating the changes in RNA processing and accumulation associated with HC-Proinduced reductions in soybean seed production.

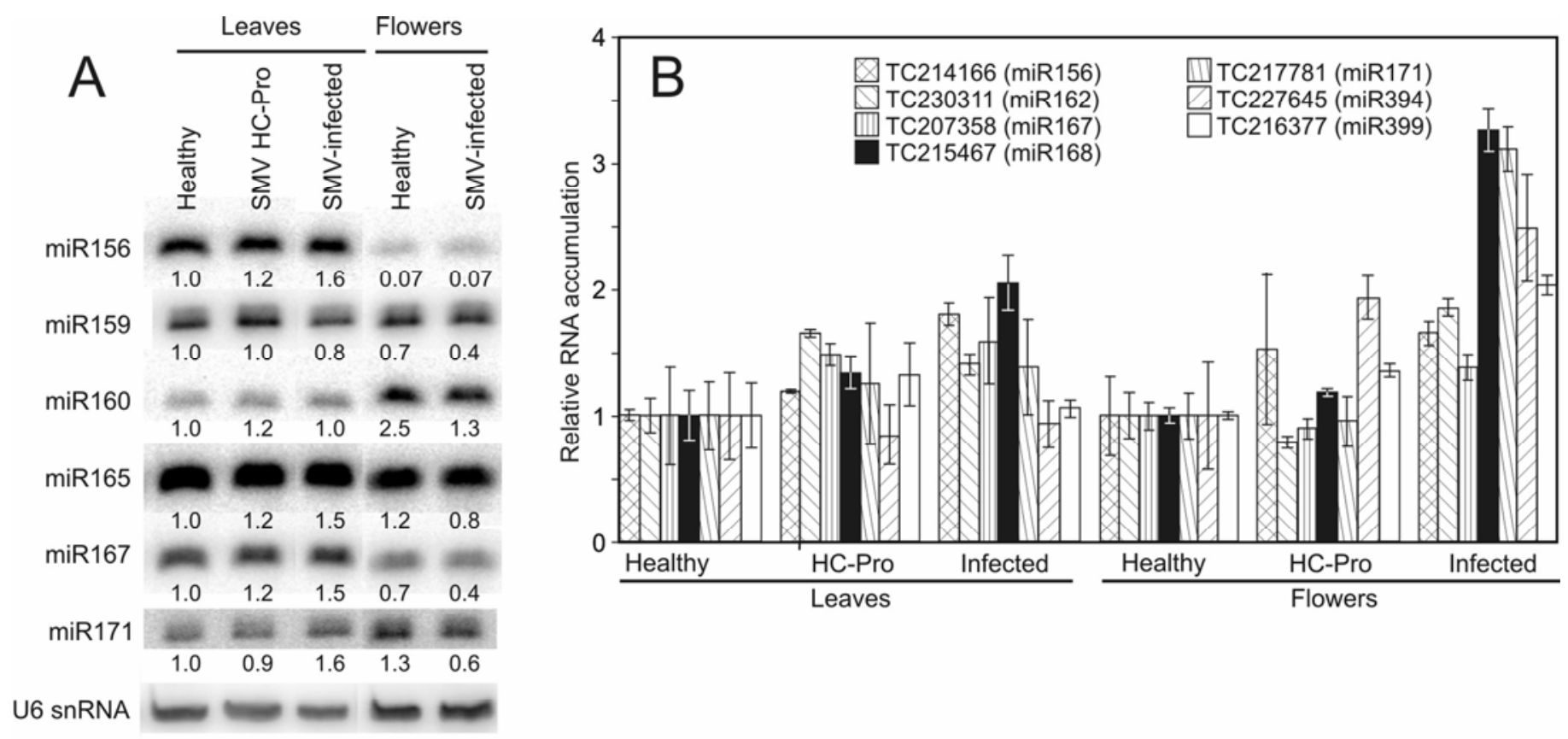

Fig. 3. Accumulation of microRNAs (miRNAs) and mRNAs putatively targeted by miRNAs in transgenic soybean plants expressing Soybean mosaic virus (SMV) G5 helper component-protease (HC-Pro) and in nontransgenic soybean plants infected with SMV. A, Low molecular weight RNAs were extracted from 5-day-old unifoliates and B2-stage flowers, separated on $15 \%$ denaturing polyacrylamide gels, blotted to nylon membranes, and probed with ${ }^{32} \mathrm{P}-$ labeled oligonucleotides complementary to Arabidopsis miR156, miR159, miR160, miR165, miR167, and miR171. After washing, membranes were exposed to a PhosphorImager (Amersham Biosciences, Piscataway, NJ) screen, and scanned. B, Relative accumulations of soybean mRNAs putatively targeted by miR156 (TC214166), miR162 (TC230311), miR167 (TC207358), miR168 (TC215467), miR171 (TC217781), miR394 (TC227645), and miR399 (TC216377) were detected by quantitative realtime reverse-transcriptase polymerase chain reaction (QRT-PCR). Unifoliate leaves and flowers were pooled from two sets of five plants and analyzed three times each. The standard errors of the means are indicated. miRNA and mRNA accumulation levels were assigned a value of 1.0 in healthy leaves and flowers. miRNA and mRNA accumulation levels for HC-Pro-transgenic and SMV-infected tissues are expressed as fold changes relative to the corresponding healthy controls. For low molecular weight RNAs, miRNA band intensities were standardized to intensities of U6 small nuclear RNA (snRNA) bands for each blot. In QRT-PCR analyses, accumulation of mRNAs was standardized to soybean actin 1 mRNA. 


\section{ACKNOWLEDGMENTS}

This research was supported by the North Central Soybean Research Program, Urbandale, IA, and the United States Department of Agriculture-Agricultural Research Service, Urbana, IL.

\section{LITERATURE CITED}

1. Aboobaker, A. A., Tomancak, P., Patel, N., Rubin, G. M., and Lai, E. C. 2005. Drosophila microRNAs exhibit diverse spatial expression patterns during embryonic development. Proc. Natl. Acad. Sci. USA 102:1801718022.

2. Allen, E., Xie, Z., Gustafson, A. M., and Carrington, J. C. 2005. microRNA-directed phasing during trans-acting siRNA biogenesis in plants. Cell 121:207-221.

3. Anandalakshmi, R., Pruss, G. J., Ge, X., Marathe, R., Mallory, A. C., Smith, T. H., and Vance, V. B. 1998. A viral suppressor of gene silencing in plants. Proc. Natl. Acad. Sci. USA 95:13079-13084.

4. Bartel, D. P. 2004. MicroRNAs: Genomics, biogenesis, mechanism, and function. Cell 116:281-297.

5. Baulcombe, D. 2004. RNA silencing in plants. Nature 431:356-363.

6. Baulcombe, D. 2005. RNA silencing. Trends Biochem. Sci. 30:290-293.

7. Bernstein, E., Caudy, A. A., Hammond, S. M., and Hannon, G. J. 2001. Role for a bidentate ribonuclease in the initiation step of RNA interference. Nature 409:363-366.

8. Chapman, E. J., Prokhnevsky, A. I., Gopinath, K., Dolja, V. V., and Carrington, J. C. 2004. Viral RNA silencing suppressors inhibit the microRNA pathway at an intermediate step. Genes Dev. 18:1179-1186.

9. Chen, X. 2004. A microRNA as a translational repressor of APETALA2 in Arabidopsis flower development. Science 303:2022-2025.

10. Chen, X. 2005. MicroRNA biogenesis and function in plants. FEBS Lett. 579:5923-5931.

11. Dezulian, T., Palatnik, J. F., Huson, D., and Weigel, D. 2005. Conservation and divergence of microRNA families in plants. Genome Biol. 6:P13.

12. Di, R., Purcell, V., Collins, G. B., and Ghabrial, S. A. 1996. Production of transgenic soybean lines expressing the Bean pod mottle virus coat protein precursor gene. Plant Cell Rep. 15:746-750.

13. Dunoyer, P., Lecellier, C. H., Parizotto, E. A., Himber, C., and Voinnet, O. 2004. Probing the microRNA and small interfering RNA pathways with virus-encoded suppressors of RNA silencing. Plant Cell 16:1235-1250.

14. Gazzani, S., Lawrenson, T., Woodward, C., Headon, D., and Sablowski, R. 2004. A link between mRNA turnover and RNA interference in Arabidopsis. Science 306:1046-1048.

15. Ghorbel, R., Lopez, C., Fagoaga, C., Moreno, P., Navarro, L., Flores, R., and Pena, L. 2001. Transgenic citrus plants expressing the Citrus tristeza virus $\mathrm{p} 23$ protein exhibit viral-like symptoms. Mol. Plant Pathol. 2:27-36.

16. Hill, J. H. 1999. Soybean mosaic virus. Pages 70-71in: Compendium of Soybean Diseases. G. L. Hartman, J. B. Sinclair, and J. C. Rupe, eds. The American Phytopathological Society, St. Paul, MN.

17. Kasschau, K. D., Xie, Z., Allen, E., Llave, C., Chapman, E. J., Krizan, K. A., and Carrington, J. C. 2003. P1/HC-Pro, a viral suppressor of RNA silencing, interferes with Arabidopsis development and miRNA function. Dev. Cell. 4:205-217.

18. Lee, Y., Tsai, J., Sunkara, S., Karamycheva, S., Pertea, G., Sultana, R., Antonescu, V., Chan, A., Cheung, F., and Quackenbush, J. 2005. The TIGR Gene Indices: Clustering and assembling EST and known genes and integration with eukaryotic genomes. Nucleic Acids Res. 33:D71-74.

19. Lim, H. S., Ko, T. S., Lambert, K. N., Kim, H. G., Korban, S. S., Hartman, G. L., and Domier, L. L. 2005. Soybean mosaic virus helper component-protease enhances somatic embryo production and stabilizes transgene expression in soybean. Plant Physiol. Biochem. 43:1014-1021.

20. Livak, K. J., and Schmittgen, T. D. 2001. Analysis of relative gene expression data using real-time quantitative PCR and the $2^{-\Delta \Delta C T}$ method. Methods 25:402-408.

21. Lu, R., Folimonov, A., Shintaku, M. H., Li, W.-X., Falk, B. W., Dawson, W. O., and Ding, S.-W. 2004. Three distinct suppressors of RNA silencing encoded by a $20-\mathrm{kb}$ viral RNA genome. Proc. Natl. Acad. Sci. USA
101:15742-15747.

22. Mallory, A. C., Reinhart, B. J., Bartel, D., Vance, V. B., and Bowman, L. H. 2002. A viral suppressor of RNA silencing differentially regulates the accumulation of short interfering RNAs and micro-RNAs in tobacco. Proc. Natl. Acad. Sci. USA 99:1522815233.

23. Mlotshwa, S., Voinnet, O., Mette, M. F., Matzke, M., Vaucheret, H., Ding, S. W., Pruss, G., and Vance, V. B. 2002. RNA silencing and the mobile silencing signal. Plant Cell 14 (suppl.):S289-301.

24. Nicola-Negri, E. D., Brunetti, A., Tavazza, M., and Ilardi, V. 2005. Hairpin RNA-mediated silencing of Plum pox virus P1 and HC-Pro genes for efficient and oredictable resistance to the virus. Transgenic Res. 14:989-994

25. Peterson, C. M., Mosjidis, C. O., Dute, R. R., and Westgate, M. E. 1992. A flower and pod staging system for soybean. Ann. Bot. 69:59-67.

26. Pfeffer, S., Dunoyer, P., Heim, F., Richards, K. E., Jonard, G., and Ziegler-Graff, V. 2002. P0 of Beet western yellows virus is a suppressor of posttranscriptional gene silencing. J. Virol. Methods 76:68156824.

27. Pruss, G., Ge, X., Shi, X. M., Carrington, J. C., and Bowman Vance, V. 1997. Plant viral synergism: The potyviral genome encodes a broad-range pathogenicity enhancer that transactivates replication of heterologous viruses. Plant Cell 9:859-868.

28. Rozen, S., and Skaletsky, H. J. 2000. Primer3 on the WWW for general users and for biologist programmers. Pages 365-386 in: Bioinformatics Methods and Protocols: Methods in Molecular Biology. S. Krawetz and S. Misener, eds. Humana Press, Totowa, NJ.

29. Sambrook, J., and Russell, D. W. 2001. Molecular Cloning: A Laboratory Manual. 3rd ed. Cold Spring Harbor Laboratory, Cold Spring Harbor, NY.

30. Savenkov, E. I., and Valkonen, J. P. 2001. Potyviral helper-component proteinase expressed in transgenic plants enhances titers of Potato leaf roll virus but does not alleviate its phloem limitation. Virology 283:285293.

31. Scholthof, H. B., Scholthof, K. B., and Jackson, A. O. 1995. Identification of Tomato bushy stunt virus host-specific symptom determinants by expression of individual genes from a potato virus $\mathrm{X}$ vector. Plant Cell 7:1157-1172.

32. Senda, M., Masuta, C., Ohnishi, S., Goto, K., Kasai, A., Sano, T., Hong, J. S., and MacFarlane, S. 2004. Patterning of virus-infected Glycine max seed coat is associated with suppression of endogenous silencing of chalcone synthase genes. Plant Cell 16:807-818.

33. Smith, H. A., Swaney, S. L., Parks, T. D., Wernsman, E. A., and Dougherty, W. G. 1994. Transgenic plant virus resistance mediated by untranslatable sense RNAs: Expression, regulation, and fate of nonessential RNAs. Plant Cell 6:1441-1453.

34. Tuteja, J. H., Clough, S. J., Chan, W. C., and Vodkin, L. O. 2004. Tissuespecific gene silencing mediated by a naturally occurring chalcone synthase gene cluster in Glycine max. Plant Cell 16:819-835.

35. van der Wilk, F., Houterman, P., Molthoff, J., Hans, F., Dekker, B., van den Heuvel, J., Huttinga, H., and Goldbach, R. 1997. Expression of the Potato leafroll virus ORF0 induces viral-disease-like symptoms in transgenic potato plants. Mol. Plant-Microbe Interact. 10:153-159.

36. Vazquez, F., Vaucheret, H., Rajagopalan, R., Lepers, C., Gasciolli, V., Mallory, A. C., Hilbert, J. L., Bartel, D. P., and Crete, P. 2004. Endogenous trans-acting siRNAs regulate the accumulation of Arabidopsis mRNAs. Mol. Cell. 16:69-79.

37. Wang, X. Y., Eggenberger, A. L., Nutter, F. W., and Hill, J. H. 2001. Pathogen-derived transgenic resistance to Soybean mosaic virus in soybean. Mol. Breed. 8:119-127.

38. Wing, J. P., Schreader, B. A., Yokokura, T., Wang, Y., Andrews, P. S., Huseinovic, N., Dong, C. K., Ogdahl, J. L., Schwartz, L. M., White, K., and Nambu, J. R. 2002. Drosophila Morgue is an F box/ubiquitin conjugase domain protein important for grim-reaper mediated apoptosis. Nat. Cell Biol. 4:451-456.

39. Zhang, C., and Ghabrial, S. A. 2006. Development of Bean pod mottle virus-based vectors for stable protein expression and sequence-specific virus-induced gene silencing in soybean. Virology 344:401-411. 